\title{
Characteristic of yellow tuna skin (Thunnus albacares) gelatin enriched with cinnamon (Cinnamomum zeylanicum) and roselle (Hibiscus sabdariffa) powder
}

\author{
${ }^{1}$ Ningrum, A., ${ }^{1}$ Hapsari, M.W., ${ }^{1}$ Perdani, A.W., ${ }^{1}$ Sutrisno, E., ${ }^{1}$ Pravitri, K.G., \\ ${ }^{1}$ Ramadhani, N.F. and ${ }^{2}$ Munawaroh, H.S.H. \\ ${ }^{1}$ Department of Food Science and Agricultural Product Technology, Faculty of Agricultural Technology, \\ Gadjah Mada University, Yogyakarta 55281 \\ ${ }^{2}$ Department of Chemistry, Faculty of Mathematics and Science, Indonesia University of Education, \\ Bandung, 40522, Indonesia
}

\begin{abstract}
Article history:
July 2020

September 2020

Keywords:

Valorization,

Gelatin,

Roselle,

Cinnamon,

Antioxidant
\end{abstract}

Received: 13 May 2020

Received in revised form: 1

Accepted: 16 July 2020

Available Online: 4

DOI:

https://doi.org/10.26656/fr.2017.4(6).225

\begin{abstract}
The current practice condition of fish processing will generate some amounts of byproducts such as skin waste. These fish processing by-products can be considered as an alternative raw material for the preparation of high protein ingredients such as gelatin. Gelatin extraction from the skin of yellowfin tuna (Thunnus albacares) was conducted by the acid process. Afterwards, the fish gelatin was mixed with cinnamon (GECP) and roselle powder (GERP) to enhance the physicochemical and functional properties of gelatin. The effects of the addition of cinnamon (GECP) and roselle powder (GERP) on the physicochemical and the functional properties such as tensile strength, hardness, viscosity, water holding capacity, oil holding capacity, total flavonoid, total phenolic, total antioxidant and flavor compounds of enriched gelatin (GECP and GERP) from tuna skin were evaluated and compared with control (without the addition of cinnamon and roselle powder). The gelatin exhibited excellent tensile strength, WHC, OHC, total flavonoid, total phenolic, and antioxidant in the presence of cinnamon and roselle powder rather than control (without addition) $(\mathrm{p}<0.05)$. The flavor analysis by using GC-MS showed more cinnamaldehyde as one important flavor compounds in GECP and where cyclohexanones can be identified as one important flavor compound in GERP. Thus, this study confirmed the improvement of physicochemical properties of gelatin enriched with cinnamon and roselle powder.
\end{abstract}

\section{Introduction}

Gelatin is a denatured fibrous protein derived from collagen by partial thermal hydrolysis. It is an important functional biopolymer that has broad applications in the food, pharmacy, and photography industries (Shyni et al., 2014; Sila et al., 2017). Fish gelatin seems the preferred raw material in biodegradable packaging and also biodegradable film production as it has good filmforming ability and is abundant in nature (Hanani and Nor-khaizura, 2019). The development of biodegradable packaging materials from fish gelatin is an effective alternative to synthetic packaging material (Ahmad et al., 2012).

Tuna is one of the worldwide favorite fish that was captured tuna is usually processed as canned food and sliced raw meat in a factory, and by-products of tuna are affluent and collected at once. Fish by-products from freshwater are seldom used as a source of raw materials for gelatin extraction. They are mainly used for animal feed supplements due to their small size (Kasankala et $a l ., 2007)$. For this reason, if the physical properties of gelatin from tuna skin resemble mammalian gelatin, tuna skin can be a replacement resource of mammalian gelatin (Cho and Kim, 2005).

Several spices and herbs are enriched in gelatin to enhance its mechanical and barrier properties. Natural substances such as spices and herb powder are highly preferable as antioxidants compared to synthetic ones yet certain disadvantages limit their usage. It has been reported that cuttlefish skin gelatin films with different herb extracts had higher tensile strength, compared with the control film. The protein-polyphenol interactions took place via hydrogen bonds and hydrophobic interactions than can lead to film strengthening. The increased amount of cross-links via such interactions 
might form a film network with the decreased free volume of the polymeric matrix, resulting in better character (Karim and Bhat, 2009; Fakhreddin and Gómez-guillén, 2018). On the other hand, a term of active packaging contains an active substance such as antioxidants that can interact with the headspace and packaged product to prolong the shelf life and quality of the product. It possesses several benefits such as the gradual release of bioactive compounds. Therefore, the continued use-up of antioxidants during storage will be decreased and there is a lower chance that the natural extract will affect the taste of the food (Hanani et al., 2019).

In Indonesia, cinnamon and roselle are mainly used for important spice and herbs that have been applied in many kinds of food. Cinnamon extract that contains many phenolic compounds, such as transcinnamaldehyde, limonene, eugenol, benzaldehyde, and cinnamyl acetate, have good antibacterial and antioxidant activities. Trans-cinnamaldehyde is a major phenolic compound, which is responsible for antibacterial and antioxidant activities (Kim and Song, 2018). Commonly roselle is added with hot water and drinks afterwards. The red anthocyanin pigments in the calyces are used as food coloring agents. The swollen calyces are the part of the plant of commercial interest as they are rich sources of Vitamin C, phytochemicals and are also used for several purposes (Ningrum et al., 2019).

The addition of herb and spice extract and also essential oils from various plants have been known to exhibit antioxidant properties, which can extend shelflife by lowering lipid oxidation in foods. Therefore, the incorporation of gelatin with spice and herbs to gelatin could be an approach to enhance the physicochemical and functional properties of gelatin. Simultaneously, gelatin with functional properties such as antioxidant activity can be gained. However, rare information regarding the improvement of physicochemical property of fish gelatin enriched with cinnamon and roselle powder has not been reported. The purpose of this research was to characterize the physicochemical characteristic gelatin enriched with Cinnamon (GECP) and Roselle Powder (GERP).

\section{Materials and methods}

\subsection{Materials}

Yellowfin tuna (Thunnus albacares) skin was provided by Fresh Fish, Yogyakarta, Indonesia. The yellowfin tuna skin was parted into abdominal and dorsal skins, the dorsal skin of yellowfin tuna was used in this study. All chemicals were purchased from Sigma Chemical Co. All reagents used in this study were analytical grade.

\subsection{Preparation of gelatin}

The yellowfin tuna skin was washed, chopped, and frozen until used. The cleaned skin was treated with an acid solution (acetic acid) for 1 day to remove the noncollagen protein and subcutaneous tissue after they were swollen. After the acid treatment, the skin was neutralized water and washed. For hot-water extraction, six volumes $(\mathrm{v} / \mathrm{w})$ of distilled water were added and heated at a temperature ranging $40-80^{\circ} \mathrm{C}$ for several hours. The extracted solution was heated until it concentrated and the filtered solution was dried at for 24 hrs in a cabinet-air dryer. Then the dried gelatin was crushed using a waring blender and then the obtained powder was obtained after 40 mesh. Obtained gelatin powder was mixed with cinnamon and roselle powder $(1: 1 \mathrm{w} / \mathrm{w})$ then characterized further including the physical and chemical properties. Cinnamon and roselle powder obtained from the local market, Yogyakarta.

\subsection{Physicochemical properties}

\subsubsection{Yield}

Gelatin yield was calculated as the percentage of the weight gelatin powder divided by the skin fish.

\subsubsection{Determination of gel strength and hardness}

Gelatin solution with a concentration of $3.32 \%$ was stirred using a magnetic stirrer until homogeneous at a temperature of $60^{\circ} \mathrm{C}$ for 15 mins. The solution was incubated for 18 hours at $10^{\circ} \mathrm{C}$. The gel strength and hardness were measured using the TAXT Plus-type texture analyzer.

\subsubsection{Determination of viscosity}

Gelatin solution was made $6.67 \%$ by weighing 6.67 $\mathrm{g}$ of gelatin then dissolved in $100 \mathrm{~mL}$ of distilled water. The viscosity was measured using the Brookfield viscometer.

\subsubsection{Water holding capacity (WHC)}

About $2.5 \mathrm{~g}$ gelatin was dissolved in $5 \mathrm{~mL}$ of distilled water and the suspension was stored at room temperature for 15 mins and shaken every 5 mins. The suspension is stirred using centrifugation at $3,000 \mathrm{rpm}$ for 15 mins. The WHC value is calculated as the percentage of the weight residue gelatin divided by the weight of the dry sample.

\subsubsection{Oil holding capacity $(\mathrm{OHC})$}

About $2.5 \mathrm{~g}$ gelatin was dissolved in $5 \mathrm{~mL}$ of glycerol and the suspension was stored at room temperature for 15 mins and shaken every 5 mins. The 
suspension is stirred using centrifugation at 3,000 rpm for 15 mins. The $\mathrm{OHC}$ value is calculated as the percentage of the weight residue gelatin divided by the weight of the suspension sample.

\subsubsection{Total flavonoid}

Total flavonoid was analyzed using aluminum chloride colorimetric method. Quercetin was used to make the calibration curve. $25 \mathrm{mg}$ of quercetin was dissolved in $25 \mathrm{~mL}$ ethanol $96 \%$ and diluted to $2,4,6,8$ and $10 \mathrm{ppm} .1 \mathrm{~mL}$ of each concentration of standard solutions, as well as $1 \mathrm{~mL}$ of each sample solution, were mixed with $10 \mathrm{~mL}$ ethanol $96 \%, 1 \mathrm{~mL}$ of aluminum chloride $2 \%$ and $1 \mathrm{~mL}$ potassium acetate $120 \mathrm{mM}$. The mixture was incubated at room temperature for an hour. The absorbance was measured at $435 \mathrm{~nm}$ using a UV-Vis spectrophotometer. Total flavonoid was expressed as weight of quercetin equivalent (QE) per gram of fresh weight sample.

\subsubsection{Total phenolic}

Phenol compound analysis can be approached by using UV-VIS Spectrophotometer method with the Folin Ciocalteu reagent. Samples $200 \mathrm{~mL}$ will be introduced to test cuvettes and then $1 \mathrm{~mL}$ of Folin Ciocalteu reagent and $0.8 \mathrm{~mL}$ of $\mathrm{Na}_{2} \mathrm{CO}_{3}$ will be added. The absorbance of all samples will be measured at $765 \mathrm{~nm}$ by using a UVVIS spectrophotometer after incubation at $30^{\circ} \mathrm{C}$ for $1.5 \mathrm{~h}$. Results will be expressed as milligram of gallic acid equivalent per gram of fresh weight sample

\subsubsection{Total antioxidant}

The radical scavenging activity against DPPH of the methanolic extract will be analyzed for measuring total antioxidant will be measured (Vadivel et al., 2012; Kumar et al., 2018). The sample $(0.1 \mathrm{~mL})$ was added to $3.9 \mathrm{~mL}$ of 2,2-diphenyl-1-picrylhydrazyl (DPPH) $\left(6 \times 10^{-5} \mathrm{~mol} / \mathrm{L}\right)$ in methanol and incubated for $30 \mathrm{~min}$ at room temperature $\left(30 \pm 1^{\circ} \mathrm{C}\right)$. The absorbance was measured at $515 \mathrm{~nm}$. DPPH solution was used as a control and methanol was used as a blank.

\subsubsection{Volatile compounds}

One gram of gelatin was a mixture with pentane: dichloromethane $(2: 1 \mathrm{v} / \mathrm{v})$. The mixture was stored in the freezer for $24 \mathrm{hrs}$. After that, the solution was filtered through a $0.45 \mu \mathrm{m}$ membrane filter. The mixture was added sodium anhydrous and evaporated. The free volatile compounds were analyzed by gas chromatography-mass spectrometry (GC-MS) using the following temperature program: initial temperature $80^{\circ} \mathrm{C}$ ramped to $250^{\circ} \mathrm{C}$ at $10^{\circ} \mathrm{C} / \mathrm{min}$, and held for $10 \mathrm{mins}$. The mass scan range was set to $\mathrm{m} / \mathrm{z} 50-300$. Helium was used as carrier gas at a constant flow rate of $1.7 \mathrm{~mL} / \mathrm{min}$. The identification of volatile compounds was based on the comparison of the mass spectra of each component with mass spectral library WILEY.

\subsection{Statistical analysis}

Analysis of variance (ANOVA) was performed using the general linear model in Minitab 17 Statistical Software (Minitab Inc., State College, PA, USA) and Tukey's multiple comparison tests for the physicochemical parameters (significance level p < $0.05)$.

\section{Results and discussion}

\subsection{Yield}

Gelatin yield is key parameters because of their economic importance for the gelatin industry and its application. In this study, the protein yield of fish gelatin was $6.29 \%$. The protein yield of gelatin samples varies depending on the raw material and extraction methods used. In the case of gelatin obtained from the skin; proximate composition, amino acid composition, acid, and alkali used in pretreatments and extraction conditions applied may show great influence on protein yield achieve. The appearance of obtained gelatin control, enriched with roselle powder and cinnamon powder can be seen in Figure 1.

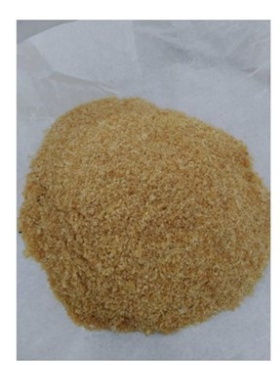

(a)

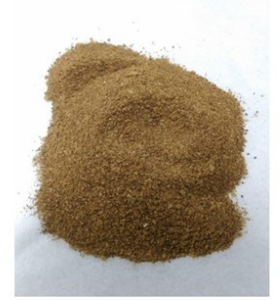

(b)

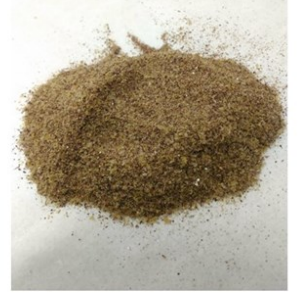

(c)
Figure 1. Appearance of (a) gelatin control extract, (b) gelatin enriched with cinnamon powder and (c) gelatin enriched with roselle powder.

\subsection{Gel strength, hardness, and viscosity}

Physical or mechanical properties of gelatin containing roselle and cinnamon powder are shown in Table 1. GERP and GECP showed the higher TS, but lower hardness and higher viscosity, compared with the control (without the addition of spice and herb powder).

Amongst all gelatin added with cinnamon powder showed the highest TS $(p<0.05)$. It indicated that the cinnamon powder components might increase the bonds in gelatin so that the tensile strength is increased. The incorporation of cinnamon powder (GECP) to gelatin could enhance the development of heterogeneous matrix, 
Table 1. Physicochemical and functional properties of control, GERP and GECP

\begin{tabular}{ccccccccc}
\hline Sample & $\begin{array}{c}\text { Tensile Strength } \\
(\mathrm{MPa})\end{array}$ & $\begin{array}{c}\text { Hardness } \\
(\mathrm{N})\end{array}$ & $\begin{array}{c}\text { Viscosity } \\
(\mathrm{cP})\end{array}$ & $\begin{array}{c}\text { WHC } \\
(\%)\end{array}$ & $\begin{array}{c}\text { OHC } \\
(\%)\end{array}$ & $\begin{array}{c}\text { Total Flavonoid } \\
(\mathrm{ppm})\end{array}$ & $\begin{array}{c}\text { Total Phenolic } \\
(\%)\end{array}$ & $\begin{array}{c}\text { Total Antioxidant } \\
(\%)\end{array}$ \\
\hline Control & $16.46^{\mathrm{a}}$ & $0.43^{\mathrm{b}}$ & $4.2^{\mathrm{a}}$ & $1.47^{\mathrm{a}}$ & $0.51^{\mathrm{a}}$ & $0.02^{\mathrm{a}}$ & $190.10^{\mathrm{a}}$ & $9.41^{\mathrm{a}}$ \\
GERP & $17.12^{\mathrm{b}}$ & $0.03^{\mathrm{a}}$ & $5.4^{\mathrm{b}}$ & $1.61^{\mathrm{b}}$ & $0.72^{\mathrm{b}}$ & $0.03^{\mathrm{b}}$ & $1243.13^{\mathrm{b}}$ & $36.95^{\mathrm{b}}$ \\
GECP & $17.78^{\mathrm{b}}$ & $0.04^{\mathrm{a}}$ & $5.6^{\mathrm{b}}$ & $1.57^{\mathrm{b}}$ & $0.92^{\mathrm{c}}$ & $0.04^{\mathrm{b}}$ & $4244.38^{\mathrm{c}}$ & $69.57^{\mathrm{c}}$ \\
\hline
\end{tabular}

Means with alphabet superscripts within columns are significantly different $(\mathrm{p}<0.05)$

leading to an increase of tensile and hardness (Ejaz et al., 2018).

Viscosity is also a key commercial characteristic of gelatin and it also varies according to not only average molecular weight and gel strength but also conditions such as $\mathrm{pH}$ and temperature. As similar to tensile strength and hardness, GECP had a higher viscosity than GERP and control $(\mathrm{p}<0.05)$ (Table 1). The addition of other components, especially cinnamon powder, in the gelatin can increase the viscosity. The viscosity of commercial gelatins generally ranges from 2.0 to $7.0 \mathrm{cP}$ and for some applications, this value is desired to be almost $13.0 \mathrm{cP}$. Viscosity is greatly influenced by differences in measurement procedures and conditions, raw material characteristics, and gelatin extraction methods (Tuğce et al., 2019).

\section{$3.3 \mathrm{WHC}$ and $\mathrm{OHC}$}

Water holding and fat binding capacities are technofunctional properties that are closely related to texture by the interaction between components such as water, oil, and other components (Shyni et al., 2014). The influence of using different sources in gelatin extraction on the techno-functional properties of the resultant gelatins was given in Table 1. GECP and GERP had a higher WHC than control $(\mathrm{p}<0.05)$. WHC was related to the number of hydrophilic amino acids and whether there were high amounts of pores and spaces within the gel network. The higher amount of hydrophilic amino acids and Hyp content caused to higher water holding capacity (Tuğce et al., 2019).

Besides that factor, the amount of water bound by protein depends on several factors, such as amino acids composition of the protein, several polar groups within the particle, availability of hydrophilic spots, $\mathrm{pH}$ of the environment, ionic strength, temperature and protein concentration (Tkaczewska et al., 2018). The waterbinding capacity of the solubilized gelatin makes it a suitable material for reducing drip loss and impairs the juiciness in frozen fish or meat products when thawed or cooked, and where the denatured protein has suffered a partial loss of its WHC (Tkaczewska et al., 2018).

In terms of oil holding capacity (OHC), statically significant differences were detected among the samples $(\mathrm{p}<0.05)$ as shown in Table 1 , GECP had a highest
OHC. Significant differences in gelatins might be caused by various levels of hydrophobic residues and tyrosine that may be affected by extraction methods (Tuğce et al., 2019). The presence of selected essential oil in roselle and cinnamon powder also can enhance the oil holding of gelatin.

The higher oil-binding capacity of GERP and GECP suggests the presence of a large proportion of hydrophobic as compared to hydrophilic groups on the surface of the protein molecules. The mechanism of fatbinding by proteins is not fully understood, but it appears to be affected by protein and lipid-protein complexes content. It is suggested that the oil absorption capacity is due to the non-polar side chains of the protein, as well as due to the different conformational features of the proteins. Our results suggest that GERP and GECP had better fat-holding capacity (Tkaczewska et al., 2018).

\subsection{Total flavonoid}

Flavonoids are a class of secondary plant phenolics with important and powerful antioxidant activities. Therefore, the amounts of total flavonoids in the extracts were determined. The total phenolics in crude extracts of gelatin were determined by the Folin-Ciocalteu method. As seen in Table 1, the highest level of total flavonoid was found in the GERP and GECP rather than control.

In GERP there are several possible flavonoids, where apparently, most of the flavonoids can be conjugated with major pigment anthocyanins in Roselle (Tsai and Huang, 2004). Flavonoids such as quercetin, luteolin or gossipetin, and their respective glycosides are also present in roselle and can be conjugated with major anthocyanin in roselle (Borrás-linares et al., 2015). The most frequent anthocyanins of roselle are cyanidin-3glucoside, delphinidin-3-glucoside, cyanidin-3sambubioside, and delphinidin-3-sambubioside (Borráslinares et al., 2015). Major flavonoids in cinnamon such as a flavonol (-)-(2R,3R)-5,7-dimethoxy-3', $4^{\prime}-$ methylenedioxy-flavan-3-ol (MFO) were able to have high antioxidant activity (Li et al., 2019). There are several evidence in vitro and in vivo certified that consumption of cinnamon is the benefit to human health because of its pharmacological functions on antidiabetes, inhibition of oxidative stress, antiinflammation, anti-hypertension, anti-microbial, and inhibition of cardiovascular disease (Borzoei et al., 2018; 
Li et al., 2019).

\subsection{Total phenolic}

The results for the total phenolic is presented in Table 1. GERP and GECP have higher phenolic compounds than control. Similar result with a little difference was reported by previous research, where the addition of herbs and spices extracts will enhance the total phenolic content in gelatin enriched with spice and herb extract (Tongnuanchan, et al., 2014; Figueroa-lopez et al., 2018; Kim et al., 2018). Several phenolic compounds have been identified in cinnamon extract e.g. gallic acid, p-hydroxybenzoic acid, phydroxybenzaldehyde, protocatechuic acid, salicylic acid, syringic acid, vanillic acid, vanillin, caffeic acid, quercetin, tannic acid, chlorogenic acid, ferulic acid, $\mathrm{p}$ coumaric acid, cinnamic acid, sinapic acid and eugenol (Hu et al., 2018). Roselle as a herbal commodity also rich in several phenolic compounds. It has strong antioxidant properties mainly due to the abundant content of polyphenolic compounds, including anthocyanin, phenolic acids, flavonoids, and many others (Wu et al., 2018).

\subsection{Total antioxidant}

Cinnamon and roselle have been confirmed to exert strong antioxidant activity (Mardiah et al., 2015; Rahadian et al., 2017; Borzoei et al., 2018; Zhang et al., 2019). It can perform as antioxidants by interruption of chain oxidation reactions, by donating a hydrogen atom, as an acceptor of free radicals, or by chelating metals. Antioxidant tests represent measuring of DPPH radical scavenging activity is attributed to hydrogen donating ability of test compounds (Dou et al., 2018). And the antioxidant capacity was positively correlated with total phenolics and total flavonoids content in the film. The adding of cinnamon and roselle would also enhance the antioxidant capacity of gelatin (Table 1).

\subsection{Volatile compounds}

The volatile determination was also performed by GC MS analysis. Several aroma compounds can be identified in Control, GERP, and GECP (Table 2). The dichloromethane peak can be identified on three samples since the extraction for those samples used dichloromethane as a solvent

Cyclohexanone as hydrocarbon derived compounds can be identified in GERP and GECP (Table 2). On the other hand, cinnamaldehyde as an important flavor compound in cinnamon can be identified in GECP. Cinnamaldehyde is one important flavor compound in cinnamon that displayed the excellent antimicrobial activity against a variety of bacteria. Gelatin enriched with essential oil from cinnamon has a long-lasting antibacterial activity on Escherichia coli, Bacillus subtilis and Staphylococcus aureus due to lease the antimicrobial active substances in the sample ( $\mathrm{Hu}$ et al., 2018).

Another research also investigated the broad spectrum of a microorganism to see the antimicrobial activity of the cinnamon extract in gelatin. Gelatin films enriched with cinnamon oil were more effective against Aspergillus niger, Rhizopus oryzae and Paecilomyces varioti than Escherichia coli and Staphylococcus aureus (Wu et al., 2017). It is suggested that the investigated antimicrobial films can be used for prolonging the shelflife of packed foods due to their bacteriostasis and barrier property of ultraviolet light (Wu et al., 2017). Another report also has shown that hagfish and chicken bone gelatin films containing cinnamon extract had good antibacterial and antioxidant activities (Kim et al., 2018).

\section{Conclusion}

Tuna skins were used in gelatin extraction as a valorization approach to reduce food waste. GERP and GECP may present better quality in several

Table 2. Aroma compounds in control, GERP and GECP

\begin{tabular}{|c|c|c|c|}
\hline \multicolumn{4}{|c|}{ Control } \\
\hline No & Retention Time (min) & Compound & $\%$ Relative Abundance \\
\hline 1 & 1.775 & Dichloromethane & 97.48 \\
\hline 2 & 6.202 & Torreyol,1-naphtalenol & 0.91 \\
\hline 3 & 6.899 & Vallencene,1-naphtalene & 0.99 \\
\hline 4 & 14.869 & Tetracosahexaene & 0.62 \\
\hline \multicolumn{4}{|c|}{ GERP } \\
\hline No & Retention Time (min) & Compound & $\%$ Relative Abundance \\
\hline 1 & 1.775 & Dichloromethane & 99.94 \\
\hline 2 & 12.74 & Cyclohexanone & 0.06 \\
\hline \multicolumn{4}{|c|}{ GECP } \\
\hline No & Retention Time (min) & Compound & $\%$ Relative Abundance \\
\hline 1 & 1.775 & Dichloromethane & 89.61 \\
\hline 2 & 7.23 & Cinnamaldehyde & 9.93 \\
\hline 3 & 12.74 & Cyclohexanone & 0.46 \\
\hline
\end{tabular}


physicochemical and functional properties compared to control (without the addition of roselle and cinnamon powder). Physicochemical properties including tensile strength, viscosity revealed, WHC, OHC Total flavonoid that GERP and GECP are more desirable than control. Differences were observed also in flavor properties in GERP and GECP. Physicochemical and functional properties of gelatins from tuna skin and enriched with roselle and cinnamon powder showed that seafood skins, which are mostly underutilized, as obtained processing waste by-products can be used as alternative raw materials in gelatin production. This study provided data suggesting that tuna skin enriched with roselle and cinnamon powder gelatins can be used further in food, pharmaceutical, nutraceuticals application industries.

\section{Conflict of interest}

The authors declare no conflict of interest in the manuscript.

\section{Acknowledgment}

Authors thankful to Toray Foundation, Japan and RTA, UGM for supporting this research.

\section{References}

Ahmad, M., Benjakul, S., Prodpran, T. and Winarni, T. (2012). Physico-mechanical and antimicrobial properties of gelatin film from the skin of unicorn leatherjacket incorporated with essential oils. Food Hydrocolloids, 28(1), 189-199. https:// doi.org/10.1016/j.foodhyd.2011.12.003

Borrás-Linares, I., Fernández-Arroyo, S., Arráez-Roman, D. and Palmeros-Suárez, P.A. (2015). Characterization of phenolic compounds, anthocyanidin, antioxidant and antimicrobial activity of 25 varieties of Mexican Roselle (Hibiscus sabdariffa). Industrial Crops and Products, 69, 385394. https://doi.org/10.1016/j.indcrop.2015.02.053

Borzoei, A., Rafraf, M., Niromanesh, S. and Farzadi, L. (2018). Effects of cinnamon supplementation on antioxidant status and serum lipids in women with polycystic ovary syndrome. Journal of Traditional Chinese Medical Sciences, 8(1), 128-133. https:// doi.org/10.1016/j.jtcme.2017.04.008

Cho, S.M., Gu, Y.S. and Kim, S.B. (2005). Extracting optimization and physical properties of yellowfin tuna (Thunnus albacares) skin gelatin compared to mammalian gelatins. Food Hydrocolloids, 19(2), 221 -229. https://doi.org/10.1016/j.foodhyd.2004.05.005

Dou, L., Li, B., Zhang, K., Chu, X. and Hou, H. (2018). Physical properties and antioxidant activity of gelatin-sodium alginate edible films with tea polyphenols. International Journal of Biological Macromolecules, 118(Part B), 1377-1383. https:// doi.org/10.1016/j.ijbiomac.2018.06.121

Ejaz, M., Arfat, Y.A., Mulla, M. and Ahmed, J. (2018). Zinc oxide nanorods/clove essential oil incorporated Type B gelatin composite films and its applicability for shrimp packaging. Food Packaging and Shelf Life, 15, 113-121. https://doi.org/10.1016/ j.fps1.2017.12.004

Fakhreddin, S. and Gómez-guillén, M.C. (2018). A stateof-the-art review on the elaboration of fish gelatin as bioactive packaging: Special emphasis on nanotechnology-based approaches. Trends in Food Science and Technology, 79, 125-135. https:// doi.org/10.1016/j.tifs.2018.07.022

Figueroa-lopez, K.J., Andrade-mahecha, M.M. and Torres-vargas, O.L. (2018). Spice oleoresins containing antimicrobial agents improve the potential use of bio-composite films based on gelatin. Food Packaging and Shelf Life, 17, 50-56. https://doi.org/10.1016/j.fps1.2018.05.005

Hanani, Z.A.N., Yee, F.C. and Nor-Khaizura, M.A.R. (2019). Effect of pomegranate (Punica granatum L .) peel powder on the antioxidant and antimicrobial properties of fish gelatin films as active packaging. Food Hydrocolloids, 89, 253-259. https:// doi.org/10.1016/j.foodhyd.2018.10.007

Hu, J., Zhang, Y., Xiao, Z. and Wang, X. (2018). Preparation and properties of cinnamon-thymeginger composite essential oil nanocapsules. Industrial Crops and Products, 122, 85-92. https:// doi.org/10.1016/j.indcrop.2018.05.058

Karim, A.A. and Bhat, R. (2009). Fish gelatin: properties, challenges, and prospects as an alternative to mammalian gelatins. Food Hydrocolloids, 23(3), 563-576. https:// doi.org/10.1016/j.foodhyd.2008.07.002

Kasankala, L.M., Xue, Y., Weilong, Y., Hong, S.D. and He, Q. (2007). Optimization of gelatine extraction from grass carp (Catenopharyngodon idella) fish skin by response surface methodology. Bioresource Technology, 98(17), 3338-3343. https:// doi.org/10.1016/j.biortech.2006.03.019

Kim, H., Beak, S. and Bin, S.K. (2018). Development of a hag fish skin gelatin film containing cinnamon bark essential oil. LWT, 96, 583-588. https:// doi.org/10.1016/j.lwt.2018.06.016

Li, A., Li, G., Li, Y., Wu, X., Ren, D. and Lou, H. (2019). Lignan and flavonoid support the prevention of cinnamon against oxidative stress related diseases. Phytomedicine, 53, 143-153. https:// doi.org/10.1016/j.phymed.2018.09.022 
Mardiah, Zakaria, F.R., Prangdimurti, E. and Damanik, R. (2015). Anti-inflammatory of Purple Roselle Extract in Diabetic Rats Induced by Streptozotocin. Procedia Food Science, 3, 182-189. https:// doi.org/10.1016/j.profoo.2015.01.020

Ningrum, A., Schreiner, M., Luna, P., Khoerunnisa, F. and Tienkink, E. (2019). Free volatile compounds in red and purple roselle (Hibiscus sabdariffa) pomace. Food Research, 3(6), 749-754.

Rahadian, D., Muhammad, A., Praseptiangga, D., Walle, D.V.D. and Dewettinck, K. (2017). Interaction between natural antioxidants derived from cinnamon and cocoa in binary and complex mixtures. Food Chemistry, 231, 356-364. https://doi.org/10.1016/ j.foodchem.2017.03.128

Shyni, K., Hema, G.S., Ninan, G., Mathew, S., Joshy, C.G. and Lakshmanan, P.T. (2014). Isolation and characterization of gelatin from the skins of skipjack tuna (Katsuwonus pelamis), dog shark (Scoliodon sorrakowah), and rohu (Labeo rohita). Food Hydrocolloids, 39, 68-76. https://doi.org/10.1016/ j.foodhyd.2013.12.008

Sila, A., Martinez-Alvarez, O., Krichen, F., GómezGuillén, M.C. and Bougatef, A. (2017). Gelatin prepared from European eel (Anguilla anguilla) skin: Physicochemical, textural, viscoelastic and surface properties. Colloids and Surfaces A: Physicochemical and Engineering Aspects, 529, 643 -650. https://doi.org/10.1016/j.colsurfa.2017.06.032

Tkaczewska, J., Kulawik, P. and Zaja, M. (2018). Characterization of carp (Cyprinus carpio) skin gelatin extracted using different pretreatments method. Food Hydrocolloids, 81, 169-179. https:// doi.org/10.1016/j.foodhyd.2018.02.048

Tongnuanchan, P., Benjakul, S. and Prodpran, T. (2014). Structural, morphological and thermal behaviour characterisations of fish gelatin film incorporated with basil and citronella essential oils as affected by surfactants. Food Hydrocolloids, 41, 33-43. https:// doi.org/10.1016/j.foodhyd.2014.03.015

Tsai, P. and Huang, H. (2004). Effect of polymerization on the antioxidant capacity of anthocyanins in Roselle. Food Research International, 37(4), 313318. https://doi.org/10.1016/j.foodres.2003.12.007

Tuğce, E., Tümerkan, A., Cansu, Ü., Boran, G. and Mac, J. (2019). Physiochemical and functional properties of gelatin obtained from tuna, frog and chicken skins. Food Chemistry, 287, 273-279. https:// doi.org/10.1016/j.foodchem.2019.02.088

Wu, H., Yang, K. and Chiang, P. (2018). Roselle Anthocyanins: Antioxidant Properties and Stability to Heat and pH. Molecules, 23(6), 1-13. https:// doi.org/10.3390/molecules23061357

Wu, J., Sun, X., Guo, X., Ge, S. and Zhang, Q. (2017). Physicochemical properties, antimicrobial activity and oil release of fish gelatin films incorporated with cinnamon essential oil. Aquaculture and Fisheries, 2 (4), 185-192. https://doi.org/10.1016/ j.aaf.2017.06.004

Zhang, J., Zou, X., Zhai, X., Huang, X. W., Jiang, C. and Holmes, M. (2019). Preparation of an intelligent $\mathrm{pH}$ film based on biodegradable polymers and roselle anthocyanins for monitoring pork freshness. Food Chemistry, 272, 306-312. https://doi.org/10.1016/ j.foodchem.2018.08.041 